NBER WORKING PAPER SERIES

\title{
TAYLOR RULES, MCCALLUM RULES AND THE TERM STRUCTURE OF INTEREST RATES
}

\author{
Michael F. Gallmeyer \\ Burton Hollifield \\ Stanley E. Zin \\ Working Paper 11276 \\ http://www.nber.org/papers/w11276 \\ NATIONAL BUREAU OF ECONOMIC RESEARCH \\ 1050 Massachusetts Avenue \\ Cambridge, MA 02138 \\ April 2005
}

This paper was prepared for the Carnegie-Rochester Conference on Public Policy. We would like to thank Ken Singleton, Marvin Goodfriend, Ben McCallum, MikeWoodford, and participants at the CarnegieRochester Conference, November 2004, for valuable comments and suggestions. Francisco Palomino provided excellent research assistance. The views expressed herein are those of the author(s) and do not necessarily reflect the views of the National Bureau of Economic Research.

(C2005 by Michael F. Gallmeyer, Burton Hollifield, and Stanley E. Zin. All rights reserved. Short sections of text, not to exceed two paragraphs, may be quoted without explicit permission provided that full credit, including (C) notice, is given to the source. 
Taylor Rules, McCallum Rules and the Term Structure of Interest Rates

Michael F. Gallmeyer, Burton Hollifield, and Stanley E. Zin

NBER Working Paper No. 11276

April 2005

JEL No. G0, G1, E4

\begin{abstract}
$\underline{\text { ABSTRACT }}$
Recent empirical research shows that a reasonable characterization of federal-funds-rate targeting behavior is that the change in the target rate depends on the maturity structure of interest rates and exhibits little dependence on lagged target rates. See, for example, Cochrane and Piazzesi (2002). The result echoes the policy rule used by McCallum (1994) to rationalize the empirical failure of the 'expectations hypothesis' applied to the term- structure of interest rates. That is, rather than forward rates acting as unbiased predictors of future short rates, the historical evidence suggests that the correlation between forward rates and future short rates is surprisingly low. McCallum showed that a desire by the monetary authority to adjust short rates in response to exogenous shocks to the term premiums imbedded in long rates (i.e. lyield-curve smoothing"), along with a desire for smoothing interest rates across time, can generate term structures that account for the puzzling regression results of Fama and Bliss (1987). McCallum also clearly pointed out that this reduced-form approach to the policy rule, although naturally forward looking, needed to be studied further in the context of other response functions such as the now standard Taylor (1993) rule. We explore both the robustness of McCallum's result to endogenous models of the term premium and also its connections to the Taylor Rule. We model the term premium endogenously using two different models in the class of affine term structure models studied in Duffie and Kan (1996): a stochastic volatility model and a stochastic price-of- risk model. We then solve for equilibrium term structures in environments in which interest rate targeting follows a rule such as the one suggested by McCallum (i.e., the "McCallum Rule"). We demonstrate that McCallum's original result generalizes in a natural way to this broader class of models. To understand the connection to the Taylor Rule, we then consider two structural macroeconomic models which have reduced forms that correspond to the two affine models and provide a macroeconomic interpretation of abstract state variables (as in Ang and Piazzesi (2003)). Moreover, such structural models allow us to interpret the parameters of the termstructure model in terms of the parameters governing preferences, technologies, and policy rules. We show how a monetary policy rule will manifest itself in the equilibrium asset-pricing kernel and, hence, the equilibrium term structure. We then show how this policy can be implemented with an interest-rate targeting rule. This provides us with a set of restrictions under which the Taylor and McCallum Rules are equivalent in the sense if implementing the same monetary policy. We conclude with some numerical examples that explore the quantitative link between these two models of monetary policy.
\end{abstract}

Michael F. Gallmeyer

Tepper School of Business

Carnegie Mellon University

Pittsburgh, PA 15213-3890

mg47@andrew.cmu.edu
Burton Hollifield

Tepper School of Business

Carnegie Mellon University

Pittsburgh, PA 15213-3890

burtonh@andrew.cmu.edu
Stanley E. Zin

Tepper School of Business

Carnegie Mellon University

Pittsburgh, PA 15213-3890

and NBER

zin@cmu.edu 


\section{Introduction}

Understanding a monetary authority's policy rule is a central question of monetary economics, while understanding the determinants of the term structure of interest rates is a central question of financial economics. Combining the two creates an important link across these two related areas of economics and has been the focus of a growing body of theoretical and empirical research. Since work by Mankiw and Miron (1986) established a clear change in the dynamic behavior of the term structure after the founding of the Federal Reserve, researchers have been working to uncover precisely the relationship between the objectives of the monetary authority and how it feeds back through aggregate economic activity and the objectives of bond market participants, to determine an equilibrium yield curve that embodies monetary policy considerations.

Of particular interest in this area is the work by McCallum (1994a). McCallum showed that by augmenting the expectations-hypothesis model of the term structure with a monetary policy rule that uses an interest rate instrument and that is sensitive to the slope of the yield curve, i.e., the risk premium on long-term bonds, the resulting equilibrium interest rate process is better able to capture puzzling empirical results based on the expectations hypothesis alone. Kugler (1997) established that McCallum's findings extend across a variety of choices for the maturity of the "long bond," as well as across a variety of countries. McCallum (1994b) applied a similar argument to foreign exchange puzzles. Although the policy rule used by McCallum was not an innovation per se since it has a relatively long tradition in the literature documenting Fed behavior (see, for example, the descriptions in Goodfriend (1991, 1993)), McCallum's innovative use of such a rule for empirical termstructure analysis leads us to refer to such a yield-curve-sensitive interest-rate-policy rule as a "McCallum Rule." This stands in contrast to other interest rate policy rules based on macroeconomic fundamentals, such as the well-known "Taylor Rule."

The link between the rejections of the expectations hypothesis, the McCallum Rule and arbitrage-free term-structure models was first discussed in Dai and Singleton (2002), who point out the need for a better understanding of the economic underpinnings for the parameters of reduced-form arbitrage-free term-structure models. They suggest both interest-rate targeting by a monetary authority and stochastic habit formation as natural directions to explore further. Following their suggestions, we study the mapping from deeper structural parameters of preferences, stochastic opportunity sets, price rigidities and monetary policy rules in macroeconomic models that incorporate stochastic volatility and a stochastic price of risk that mirror the arbitrage-free term-structure models that have become standard in the empirical finance literature.

The benefits of integrating macroeconomic models with arbitrage-free term-structure models will depend on the perspective one takes. From a purely empirical asset-pricing perspective, building term-structure models based on macroeconomic factors has proven to be quite successful. Ang and Piazzesi (2003), following work by Piazzesi (2001), have shown that a factor model of the term structure that imposes no-arbitrage conditions can provide a better empirical model of the term structure than a model based on unobserved factors 
or latent variables alone. Estrella and Mishkin (1997), Evans and Marshall (1998, 2001), and Hördahl, Tristani and Vestin (2003) also provide evidence of the benefits of building arbitrage-free term-structure models with macroeconomic fundamentals.

From a monetary economics perspective, using information about expectations of future macroeconomic variables as summarized in the current yield curve is attractive since highquality financial-market data is typically available in real time. Monetary policy rules based on such information, therefore, may be better suited for dealing with immediate economic conditions, rather than rules based on more-slowly-gathered macroeconomic data (see, for example, Rudebush (1998), Cochrane and Piazzesi (2002), and Piazzesi and Swanson (2004), among others).

Some recent work seeks to combine these two dimensions. Rudebusch and Wu (2004) and Ang, Dong and Piazzesi (2004) investigate the empirical consequences of imposing an optimal Taylor Rule on the performance of arbitrage-free term-structure models.

The McCallum Rule, however, has not yet been studied in the same rigorous fashion in the context of a structural macroeconomic model as the Taylor Rule. Such an analysis would allow us to go beyond the initial empirical motivation for this rule and study its broader properties relative to an optimal monetary policy rule. In this paper, we extend the theoretical term-structure models on which these empirical macro-finance studies are based to include both a formal macroeconomic model and an explicit monetary policy rule. Our goal is summarized by Cochrane and Piazzesi (2002) who estimate a Fed policy rule and find that when setting target rates, "the Fed responds to long-term interest rates, perhaps embodying inflation expectations, and to the slope of the term structure, which forecasts real activity." In other words, we ask whether a rule that directly responds to macroeconomic fundamentals such as inflation or inflation expectations and real output or expected real output, e.g., a Taylor Rule, can be equivalent to a McCallum Rule in which short-term interest rates are set in response to term structure considerations, as suggested by the work of Cochrane and Piazzesi (2002). If so, then what are the theoretical restrictions on both the asset-pricing behavior of the economy and macroeconomic behavior of the economy that result in this equivalence?

In the models we study, there is a generic equivalence in these policy rules. McCallum's rule has the interest rate responding to yield spreads and lagged interest rates. But equilibrium yield spreads are functions of the current state of the economy, hence, the McCallum Rule could be written as a rule relating the interest rate to the state of the economy. Since all other interest rate rules have this basic form, there is a trivial sense in which these rules are equivalent. However, the mapping from the state of the economy to the equilibrium interest rate when the monetary authority follows a McCallum Rule is not arbitrary. Rather it is a highly restrictive function of the deeper parameters of the model. The equivalence we explore, therefore, is at a more quantitative level. That is, we explore whether sensible parameter values for the deeper parameter of the economy lead to comparable equilibrium interest rate processes under reasonable parameter values for the McCallum Rule as it does for reasonable parameter values for the Taylor Rule. 
We begin in Section 2 by reviewing McCallum's basic argument and consider an extension to a broad class of equilibrium term-structure models with a particularly convenient linearfactor structure. We extend McCallum's result to the case of an endogenous risk premium and show that his conclusions are essentially unchanged. In Section 4 we develop a simple "New Keynesian" macroeconomic model based on Clarida, Galí and Gertler (1999) and study the equilibrium in this economy when the monetary authority follows a Taylor Rule. In addition, we establish the conditions under which the McCallum Rule and the Taylor Rule are equivalent. This equivalence depends critically on the link between fundamental macroeconomic shocks to inflation and output and the risk premiums earned in the longterm bond market. In Section 6 we provide numerical examples that allow us to compare and contrast the McCallum Rule to the Taylor Rule that both implement the same monetary policy. The final section summarizes and concludes the paper.

\section{The McCallum Rule}

We begin with a brief review of the McCallum (1994) model of the term structure that embodies an active monetary policy with an interest rate instrument. Denote the price at date $t$ of a default-free pure-discount bond that pays 1 with certainty at date $t+n$ as $b_{t}^{(n)}$. The continuously compounded yield on this bond, $r_{t}^{(n)}$, is defined as:

$$
b_{t}^{(n)} \equiv \exp \left(-n r_{t}^{(n)}\right)
$$

or

$$
r_{t}^{(n)}=-\frac{1}{n} \log b_{t}^{(n)}
$$

We refer to the interest rate, or short rate, as the yield on the bond with the shortest maturity under consideration, $r_{t} \equiv r_{t}^{1}$. The one-period forward rate, $f_{t}^{(n)}$, implicit in the price of an $n$ period bond is defined in a similar way,

$$
b_{t}^{(n)} \equiv b_{t}^{(n-1)} \exp \left(-f_{t}^{(n)}\right)
$$

or

$$
f_{t}^{(n)} \equiv \log \left(b_{t}^{n-1} / b_{t}^{n}\right) .
$$

This implies a relationship between yields and forward rates:

$$
r_{t}^{(n)}=\frac{1}{n} \sum_{k=1}^{n} f_{t}^{(k)} .
$$

A simple version of the "expectations hypothesis" relates the forward rate to the expectation of a comparably timed future short rate, and a risk premium. In other words, the risk premium, $\xi_{t}^{(n)}$, is defined by the equation

$$
f_{t}^{(n)} \equiv E_{t} r_{t+n-1}+n \xi_{t}^{(n)}
$$


Combining equations (1) and (2) for the case of a 2-period bond, $n=2$, results in the familiar equation

$$
r_{t}^{(2)}=\frac{1}{2}\left(r_{t}+E_{t} r_{t+1}\right)+\xi_{t}^{(2)}
$$

Define the short-rate forecast error as $\epsilon_{t+1}^{r} \equiv r_{t+1}-E_{t} r_{t+1}$, and rewrite (3) as

$$
r_{t+1}-r_{t}=2\left(r_{t}^{(2)}-r_{t}\right)-\xi_{t}^{(2)}-\epsilon_{t+1}^{r} \text {. }
$$

When the risk premium is a constant, equation (4) forms a regression that can be estimated with observed bond-market behavior. There is also nothing particularly special about the 2-period maturity since we could imagine studying the comparable regression at any maturity for which we have data. The well-known Fama and Bliss (1987) empirical puzzle demonstrates that regressions based on equation (4) are strongly rejected in the data, and the coefficient on the term premium, $r_{t}^{(2)}-r_{t}$, is significantly smaller than predicted by equation (4). These empirical facts have been established in a wide variety of subsequent studies summarized in Backus, Foresi, Mazumdar and Wu (2001). Dai and Singleton (2002, 2003) study these rejections in the context of a wide variety of models of the risk premium, $\xi_{t}^{(2)}$.

The expectations hypothesis as stated is not a very complete model since it neither specifies the stochastic process for exogenous shocks or the mapping from these shocks to endogenous bond prices and yields. By combining a specification of the risk-premium process with an interest rate model, McCallum (1994) was able to integrate the expectations hypothesis and an analysis of a simple monetary policy rule that uses the short-rate as an instrument. In other words, he specified additional restrictions on the expectations hypothesis that embody an active monetary policy and an exogenous risk premium. We refer to the rule as the "McCallum Rule," which takes the form

$$
r_{t}=\mu_{r} r_{t-1}+2 \mu_{f}\left(r_{t}^{(2)}-r_{t}\right)+\varepsilon_{t}
$$

where $\varepsilon_{t}$ is a state variable summarizing the other exogenous determinants of monetary policy. The monetary policy rule implies that the monetary authority intervenes in the short-bond market to try to achieve two (perhaps conflicting) goals: "short-rate smoothing" governed by the parameter $\mu_{r}$ and "yield-curve smoothing" governed by the parameter $\mu_{f}$. We will return to the motivation for and the practical implications of this monetary policy rule shortly, but it is first instructive to see how the McCallum Rule affects our interpretation of the strong empirical rejections of the expectations hypothesis.

Combining equations (4) with (5) yields a linear stochastic difference equation for the interest rate:

$$
E_{t} r_{t+1}=\left(\frac{1+\mu_{f}}{\mu_{f}}\right) r_{t}-\frac{\mu_{r}}{\mu_{f}} r_{t-1}-\xi_{t}^{(2)}-\frac{1}{\mu_{f}} \varepsilon_{t} .
$$

Using a first-order process for the risk premium,

$$
\xi_{t}^{(2)}=(1-\rho) \theta^{\xi}+\rho \xi_{t-1}^{(2)}+\epsilon_{t}^{\xi},
$$


where $\epsilon_{t}^{\xi}$ is exogenous noise, and $|\rho|<1$, McCallum (1994) shows that a stable solution, when it exists, is given by a linear function of the pre-determined or exogenous state variables,

$$
r_{t}=M_{0}+M_{1} r_{t-1}+M_{2} \xi_{t}^{(2)}+M_{3} \varepsilon_{t}
$$

where

$$
M_{1}=\frac{1+\mu_{f}-\left[\left(1+\mu_{f}\right)^{2}-4 \mu_{f} \mu_{r}\right]^{1 / 2}}{2 \mu_{f}},
$$

is the equilibrium interest-rate-feedback coefficient which, in turn, determines the other coefficients:

$$
\begin{aligned}
M_{0} & =\frac{\mu_{f} M_{2}(1-\rho) \theta^{\xi}}{1+\mu_{f}(1-M 1)}, \\
M_{2} & =\frac{2 \mu_{f}}{1+\left(1-\rho-M_{1}\right) \mu_{f}}, \\
M_{3} & =\frac{1}{1+\left(1-M_{1}\right) \mu_{f}} .
\end{aligned}
$$

Note that as a small generalization of McCallum's original specification, we have added a constant drift term, $\theta^{\xi}$, to the risk-premium autoregression. This addition will help facilitate comparisons with the endogenous risk-premium models below.

A particularly simple special case is extreme interest rate smoothing, $\mu_{r}=1$, as studied by Kugler (1997), which implies and interest rate solution:

$$
r_{t}=\frac{2 \mu_{f}^{f}(1-\rho) \theta^{\xi}}{1-\rho \mu_{f}}+r_{t-1}+\frac{2 \mu_{f}}{1-\rho \mu_{f}} \xi_{t}^{(2)}+\varepsilon_{t},
$$

and an expectations-hypothesis-like regression based on the equation

$$
E_{t}\left(r_{t+1}-r_{t}\right)=\frac{\mu_{f} \theta^{\xi}}{1-\mu_{f}}+2 \rho \mu_{f}\left(r_{t}^{(2)}-r_{t}\right)
$$

which combines equation (8) with the risk-premium equation (6). It is evident, therefore, that the McCallum Rule combined with the expectations hypothesis can account for the Fama-Bliss type of empirical findings. The coefficient from a regression motivated by equation (4) must now be interpreted using the result in equation (9). The apparent downward bias is simply a reflection of the combination of persistence in the risk premium $\rho$ and the monetary authority's yield-curve smoothing policy $\mu_{f}$. Since it is reasonable to think of either or both of these parameters as numbers significantly less than 1, the downward bias documented in the empirical literature is a natural finding for this model.

Note also that if $\rho=0$ and there is no persistence in the risk premium, or if the monetary authority is unconcerned with the slope of the yield curve, $\mu_{f}=0$, the model implies that there is nothing to be learned from the traditional expectations-hypothesis regression. There is no longer a link between changes in the interest rate and the forward premium: the interest rate is engineered by the monetary authority to always follow a random walk, 
and the risk premium is simply unforecastable noise. Therefore, for McCallum's integration of monetary policy and a term-structure theory to be useful in rationalizing such empirical findings, persistence in the risk premium and sensitivity of monetary policy to the slope of the yield curve are central assumptions.

\section{Endogenous Risk Premiums and the McCallum Rule}

A limitation in McCallum's analysis is the exogeneity of the risk premium. The deeper source of the risk premium and how factors driving the risk premium might be related to factors that affect the interest rate are left unspecified. Since McCallum's analysis, however, there have been numerous advances in the area of equilibrium term-structure modelling that capture many of these effects. Moreover, as summarized by Dai and Singleton (2000, 2002, 2003) much of this literature has focused on linear rational expectations models (termed "affine models") and have been directed at similar empirical puzzles as those that motivated McCallum's work. To re-interpret McCallum's findings in the context of this newer class of models, we turn now to a log-linear model of multi-period bond pricing that anticipates the log-linear macroeconomic model in which we will imbed our analysis of monetary policy rules.

We begin with the "fundamental equation" of asset pricing as applied to the equilibrium price of default-free, pure-discount bonds:

$$
b_{t}^{(n)}=E_{t}\left[m_{t+1} b_{t+1}^{(n-1)}\right]
$$

where the stochastic process $m_{t+1}$ is referred to as the "asset-pricing kernel" or "stochastic discount factor." Note that since $b_{t}^{(0)}=1$ by definition, bond prices of all maturities can be derived recursively from this fundamental equation given a specification of the pricing kernel. In the structural macroeconomic models below, $m_{t+1}$ will be interpreted as the equilibrium marginal rate of intertemporal substitution of the representative agent. ${ }^{5}$

We first adopt the Backus, Foresi, Mazumdar and Wu (2001) discrete-time version of the model of Duffie and Kan (1996). The model begins with a characterization of the dynamic evolution of the state variables, including stochastic volatility. The state variables are then linked to the pricing kernel, which is then used to solve for arbitrage-free discount bond prices of all maturities. The stochastic volatility of state variables results in a statedependent risk-premium.

We next turn to a discrete-time version of the model of Duffee (2002), which assumes a constant volatility structure for the state variables, but allows for a state-dependent "price of risk" in the pricing-kernel specification, which translates to a state-dependent risk-premium in arbitrage-free discount bond prices. Dai and Singleton $(2002,2003)$ have shown that there is considerably more empirical support for term-structure models based

\footnotetext{
${ }^{5}$ For a comprehensive treatment of this approach to asset pricing, see Singleton (2005).
} 
on the Duffee model than the stochastic volatility model. We present both models here to demonstrate the robustness of McCallum's original result and to anticipate the alternative specifications of the structural macroeconomic models to follow.

\subsection{McCallum meets Duffie-Kan}

Denote the state variables of the model as the $k \times 1$ vector $s_{t}$. The dynamics of the state variables are modelled using a first-order vector autoregression:

$$
s_{t+1}=(I-\Phi) \theta+\Phi s_{t}+\Sigma\left(s_{t}\right)^{1 / 2} \epsilon_{t+1},
$$

where $\epsilon_{t} \sim$ iid $N(0, I), \Phi$ is a $k \times k$ matrix of autoregressive parameters assumed to be stable, and $\theta$ is a $k \times 1$ vector of drift parameters. Note that this notation allows for the conditional covariance matrix, $\Sigma\left(s_{t}\right)$, to also depend on the state variable. Below we will consider particular functional forms for this dependence.

Duffie and Kan (1996) studied the class of "affine" term-structure models in which the equilibrium or arbitrage-free prices of multi-period default-free pure discount bonds were affine functions of the model's state variables:

$$
-\log b_{t}^{(n)}=A(n)+B(n)^{\top} s_{t},
$$

where $A(n)$ is a scalar and $B(n)$ is a $k \times 1$ vector of parameters that depend on maturity $n$, but are otherwise constant functions of deeper parameters in the economy. Below we will derive $A(n)$ and $B(n)$ as functions of the parameters governing the stochastic evolution of the state variables and the parameters governing the "price of risk." This affine structure for the log of bond prices implies an affine structure for continuously compounded yields:

$$
r_{t}^{(n)}=-n^{-1} \log b_{t}^{(n)}=\frac{A(n)}{n}+\frac{B(n)^{\top}}{n} s_{t} .
$$

As described in the previous section, the McCallum Rule imposes a policy-motivated restriction on the co-movements of bond yields of different maturities. To facilitate discussions of such a restriction, it is helpful to re-write the affine model in terms of a more natural state space. In particular, we will rotate the system of equations defined by (??) to relate the short rate to endogenous term premiums. Note that this is an arbitrary choice and we equivalently could choose any $k$ variables to form the state space provided we maintain the basic structure implied by equation (??).)

Define the new $k \times 1$ vector of state variables, $\hat{r}_{t}$, to include the short rate and the yield spread on $(k-1)$ bonds of longer maturity. For notational simplicity, we will use yields of maturities $2,3, \ldots, k$ :

$$
\hat{r}_{t} \equiv\left[r_{t}, r_{t}^{(2)}-r_{t}, \ldots, r_{t}^{(k)}-r_{t}\right]^{\top} .
$$


Obviously, this state variable is an affine function of the original state variable, $s_{t}$, which we can define as

$$
\hat{r}_{t}=\mathcal{A}+\mathcal{B} s_{t},
$$

where the $k \times 1$ matrix $\mathcal{A}$ is defined as

$$
\mathcal{A} \equiv\left[\begin{array}{c}
A(1) \\
\frac{A(2)}{2}-A(1) \\
\vdots \\
\frac{A(k)}{k}-A(1)
\end{array}\right],
$$

and the $k \times k$ matrix $\mathcal{B}$ is defined as

$$
\mathcal{B} \equiv\left[\begin{array}{c}
B(1)^{\top} \\
\frac{B(2)^{\top}}{2}-B(1)^{\top} \\
\vdots \\
\frac{B(k)^{\top}}{k}-B(1)^{\top}
\end{array}\right] .
$$

Provided the matrix $\mathcal{B}$ has full rank, we can also write equation (11) as

$$
s_{t}=\mathcal{B}^{-1}\left(\hat{r}_{t}-\mathcal{A}\right) .
$$

Hence, the new state variable also follows a first-order vector autoregression:

$$
\hat{r}_{t}=\mathcal{C}+\mathcal{D} \hat{r}_{t-1}+\mathcal{S}\left(s_{t}\right) \epsilon_{t},
$$

where the coefficients of this vector autoregression are given by

$$
\begin{aligned}
\mathcal{C} & =\mathcal{A}+\mathcal{B}(I-\Phi) \theta-\mathcal{B} \Phi \mathcal{B}^{-1} \mathcal{A} \\
\mathcal{D} & =\mathcal{B} \Phi \mathcal{B}^{-1}, \text { and } \\
\mathcal{S}\left(s_{t}\right) & =\mathcal{B} \Sigma\left(s_{t}\right)^{1 / 2} .
\end{aligned}
$$

To relate this rotation to a McCallum Rule interest rate equation, we partition the parameter matrices of the vector autoregression to isolate the short-rate process, $r_{t}$ :

$$
\begin{gathered}
\mathcal{D}=\left[\begin{array}{cc}
\mathcal{D}_{11} & \mathcal{D}_{12} \\
(1 \times 1) & (1 \times(k-1)) \\
\mathcal{D}_{21} & \mathcal{D}_{22} \\
((k-1) \times 1) & ((k-1) \times(k-1))
\end{array}\right], \\
\mathcal{C}=\left[\begin{array}{c}
\mathcal{C}_{1} \\
{ }_{(1 \times 1)} \\
\mathcal{C}_{2} \\
((k-1) \times 1)
\end{array}\right], \text { and } \mathcal{S}=\left[\begin{array}{c}
\mathcal{S}_{1} \\
\mathcal{(}_{2} \\
\mathcal{S}_{2} \\
((k-1) \times k)
\end{array}\right],
\end{gathered}
$$

where, for simplicity, we have suppressed the dependence of $\mathcal{S}$ on $s_{t}$. 
With this structure in place, we can now solve for the relationship between the short rate and the vector of yield spreads in $\hat{r}_{t}$ :

$$
\begin{aligned}
r_{t} & =\left(\mathcal{C}_{1}-\mathcal{D}_{12} \mathcal{D}_{22}^{-1} \mathcal{C}_{2}\right)+\left(\mathcal{D}_{11}-\mathcal{D}_{12} \mathcal{D}_{22}^{-1} \mathcal{D}_{21}\right) r_{t-1} \\
& +\mathcal{D}_{12} \mathcal{D}_{22}^{-1}\left[r_{t}^{(2)}-r_{t}, r_{t}^{(3)}-r_{t}, \ldots, r_{t}^{(k)}-r_{t}\right]^{\top} \\
& +\left(\mathcal{S}_{1}-\mathcal{D}_{12} \mathcal{D}_{22}^{-1} \mathcal{S}_{2}\right) \epsilon_{t} .
\end{aligned}
$$

This equation provides a straightforward interpretation of the McCallum Rule in the context of arbitrage-free term-structure models. A McCallum Rule such as equation (5) can be viewed through equation (12) as simply a set of restrictions on the values of the parameters governing the equilibrium relationship between the short rate and higher-order yield spreads. Applying such restrictions to equation (12) generalizes the logic that lead to equations (7) and (8), and the regression result of equation (9) to allow for an endogenous risk premium and a higher-dimensional state space.

To understand the implications of such restrictions at a more fundamental level, we first consider more specific affine models that will determine the values of the matrices $A(n)$ and $B(n)$ as functions of the parameters of a state-variable process and of a price-of-risk process. We then turn to a structural macroeconomic model that will allow us to interpret the values of the parameters of the state-variable process and the price-of-risk process in terms of macroeconomic fundamentals (e.g., preferences, technology, monopolistic price setting, and monetary policy rules). This final step allows us to compare and contrast the implications of a McCallum Rule to other policy rules such as the Taylor Rule.

\subsection{Stochastic Volatility}

Denoting the $k$ state variables of the model as the vector $s_{t}$, the dynamics of the state variables are modelled using a first-order vector autoregression with conditional volatility of the "square-root" form:

$$
s_{t+1}=(I-\Phi) \theta+\Phi s_{t}+\Sigma\left(s_{t}\right)^{1 / 2} \epsilon_{t+1},
$$

where $\epsilon_{t} \sim$ iid $N(0, I), \Phi$ is a $k \times k$ matrix of autoregressive parameters assumed to be stable, $\theta$ is a $k \times 1$ vector of drift parameters, and the conditional volatility process is given by:

$$
\Sigma\left(s_{t}\right)=\operatorname{diag}\left\{\alpha_{i}+\beta_{i}^{\top} s_{t}\right\}, i=1,2, \ldots k .
$$

Since the variance must by positive, the parameters, $\alpha_{i}$ and $\beta_{i}$, of the volatility process satisfy a set of sufficient conditions to insure this (see Backus, Foresi, Mazumdar and Wu (2001)).

The asset-pricing kernel is related to these state variables by the equation:

$$
-\log m_{t+1}=\Gamma_{0}+\Gamma_{1}^{\top} s_{t}+\lambda^{\top} \Sigma\left(s_{t}\right)^{1 / 2} \epsilon_{t+1} .
$$


The $k \times 1$ vector $\lambda$ is referred to as the "price of risk." The log-linear structure implies that the $\log$ of the pricing kernel inherits the conditional log normality of the state variable process.

We can use this pricing kernel to solve for arbitrage-free discount bond prices. By the definition of the pricing kernel, bond prices can be found recursively using the definition of the pricing kernel,

$$
b_{t}^{(n)}=E_{t}\left[m_{t+1} b_{t+1}^{(n-1)}\right]
$$

Given the conditional log-normality of the pricing kernel, it is natural to conjecture a bondprice process that is log-linear in the state variables, $s_{t}$ :

$$
-\log b_{t}^{(n)}=A(n)+B(n)^{\top} s_{t},
$$

where $A(n)$ is a scalar and $B(n)$ is a $k \times 1$ vector of undetermined coefficients. Similarly, the continuously compounded yields will be linear functions of the state variables:

$$
r_{t}^{(n)}=-n^{-1} \log b_{t}^{(n)}=\frac{A(n)}{n}+\frac{B(n)^{\top}}{n} s_{t} .
$$

The bond-price/yield coefficients can be found recursively given the initial conditions $A(0)=$ 0 and $B(0)=0$, (i.e., the price of an instantaneous payment of 1 is 1 ). The recursions are given by:

$$
A(n+1)=\Gamma_{0}+A(n)+B(n)^{\top}(I-\Phi) \theta-\frac{1}{2} \sum_{j=1}^{k}\left(\lambda_{j}+B(n)_{j}\right)^{2} \alpha_{j}
$$

and

$$
B(n+1)^{\top}=\Gamma_{1}^{\top}+B(n)^{\top} \Phi-\frac{1}{2} \sum_{j=1}^{k}\left(\lambda_{j}+B(n)_{j}\right)^{2} \beta_{j}^{\top} .
$$

The interest rate process is given by:

$$
\begin{aligned}
r_{t}=-\log b_{t}^{(1)} & =A(1)+B(1)^{\top} s_{t} \\
& =\left(\Gamma_{0}-\frac{1}{2} \sum_{j=1}^{k} \lambda_{j}^{2} \alpha_{j}\right)+\left(\Gamma_{1}^{\top}-\frac{1}{2} \sum_{j=1}^{k} \lambda_{j}^{2} \beta_{j}^{\top}\right) s_{t} .
\end{aligned}
$$

Extending this to a 2-period-maturity bond allows us to define the state-dependent risk premium, $\xi_{t}^{(2)}$, in a natural way. Define the risk premium using the expectations hypothesis as in equation (3):

$$
\begin{aligned}
r_{t}^{(2)} & \equiv \frac{1}{2}\left(r_{t}+E_{t} r_{t+1}\right)+\xi_{t}^{(2)} \\
& =\frac{1}{2}\left[A(1)+B(1)^{\top} s_{t}+A(1)+B(1)^{\top} E_{t} s_{t+1}\right]+\xi_{t}^{(2)} \\
& =A(1)+\frac{1}{2}\left[B(1)^{\top}(I-\Phi) \theta+B(1)^{\top}(I+\Phi) s_{t}\right]+\xi_{t}^{(2)} .
\end{aligned}
$$


Since we also know that the 2-period yield satisfies the equilibrium pricing condition:

$$
r_{t}^{(2)}=\frac{A(2)}{2}+\frac{B(2)^{\top}}{2} s_{t},
$$

we can write the risk premium on a 2 -period bond as

$$
\xi_{t}^{(2)}=\sum_{i=1}^{k} \hat{\Gamma}_{i}\left(\alpha_{i}+\beta_{i}^{\top} s_{t}\right)
$$

where

$$
\hat{\Gamma}_{i} \equiv-\frac{1}{2}\left(\Gamma_{1 i}-\frac{1}{2}\left[\sum_{j=1}^{k} \lambda_{j}^{2} \beta_{j}^{\top}\right]_{i}\right)\left(\lambda_{i}+\frac{1}{2}\left(\Gamma_{1 i}-\frac{1}{2}\left[\sum_{j=1}^{k} \lambda_{j}^{2} \beta_{j}^{\top}\right]_{i}\right)\right) .
$$

Naturally, this logic extends to the definition of a risk premium for any maturity bond, using the general definition of the risk premium:

$$
\begin{aligned}
\xi_{t}^{(n)} & =r_{t}^{(n)}-\frac{1}{n}\left[(n-1) r_{t}^{(n-1)}+E_{t} r_{t+n-1}\right] \\
& =\frac{A(n)-A(n-1)}{n}+\frac{B(n)^{\top}-B(n-1)^{\top}}{n} s_{t}-\frac{1}{n} E_{t} r_{t+n-1} .
\end{aligned}
$$

The source of the state-dependent risk premium in this model is through the state-dependent conditional variance of the state variables and the pricing kernel. Absent this volatility, i.e., $\beta=0$, the risk premium is a constant function of the maturity and, hence, would provide no scope for an active policy response as characterized by the McCallum Rule. Relating the endogenous risk premium back to our earlier discussion of McCallum's model, the equilibrium risk premium in this model inherits the dynamics of the state variables, $s_{t}$. McCallum's specification for the dynamics of the risk premium therefore translates directly to our specification of the dynamics of the underlying state variables, provided the risk premium is state dependent, $\beta_{i} \neq 0$, for at least one value of $i$. In the next section we will relate these state variables to the shocks in a more complete macroeconomic model. Note, however, that we can repeat the McCallum Rule analysis for this more general termstructure model which will allow us to characterize a similar sort of expectations-hypothesisregression as in McCallum's analysis.

To see this most clearly, consider the case of a single-factor model, $k=1$. Equations (18) and (13) imply that the dynamics of the risk premium in the one-factor model are:

$$
\xi_{t+1}^{(2)}=(1-\Phi) \theta^{\xi}+\Phi \xi_{t}^{(2)}-\frac{\hat{\Gamma} \beta}{2} \Sigma\left(s_{t}\right)^{1 / 2} \epsilon_{t+1},
$$

where, in obvious notation, all parameters are the natural scalar equivalents of the parameters in equation (13), and the risk-premium drift term is given by

$$
\theta^{\xi}=-\frac{\hat{\Gamma}(\alpha+\beta \theta)}{2} \text {. }
$$


Note the important similarity between this endogenous risk-premium and McCallum's original exogenous specification: They are both $\operatorname{AR}(1)$ processes. They do, however, have different drift parameters (the drift in equation (19) is a function of the deeper parameters of the state-variable process and the pricing kernel), and the risk premium in equation (19) has a state-dependent conditional variance. Neither of these latter two points is relevant for the interpretation of Fama-Bliss-like regression results. The equilibrium interest rate process for this model is identical to that in equation (7) with a suitable redefinition of the risk-premium drift term, $\theta^{\xi}$. Therefore, the interpretation of the slope coefficient in a regression like equation (9) is unchanged. Once again, turning to the special case of extreme interest rate smoothing, $\mu_{r}=1$, we have

$$
r_{t}=-\frac{\mu_{f}^{2} \hat{\Gamma}(\alpha+\beta \theta)(1-\Phi)}{\left(1-\mu_{f}\right)\left(1-\Phi \mu_{f}\right)}+r_{t-1}+\frac{2 \mu_{f}}{1-\Phi \mu_{f}} \xi_{t}^{(2)}+\varepsilon_{t},
$$

which, aside from a nonzero intercept term, implies an expectations-hypothesis regression comparable to equation (9):

$$
E_{t}\left(r_{t+1}-r_{t}\right)=-\frac{\mu_{f} \hat{\Gamma}(\alpha+\beta \theta)(1-\Phi)}{1-\mu_{f}}+2 \Phi \mu_{f}\left(r_{t}^{(2)}-r_{t}\right) .
$$

Equation (20) demonstrates that, even when the risk premium is determined endogenously, the apparent downward bias of a Fama-Bliss-type regression can be interpreted as a reflection of the combination of persistence in the risk premium (which in this case is the same as the persistence in the state variable), and the monetary authority's yield-curve smoothing policy, $\mu_{f}$. In other words, McCallum's result carries over directly to the endogenous risk-premium model with stochastic volatility.

Dai and Singleton $(2002,2003)$ have shown that a model in which the state dependence of the risk premium is the result of a state-dependent price of risk, rather than volatility, is equally tractable yet provides a much better empirical model. In light of these facts, we now explore McCallum's result using an alternative log-linear term-structure model. We will work with a discrete-time version of the model of Duffee (2002) (see also, Brandt and Chapman (2003), Ang and Piazzesi (2003), and Dai and Philippon (2004)).

\subsection{The Stochastic Price-of-Risk Model}

Assume that the dynamics of the state variables, $s_{t}$, are as specified in equation (13), however, assume that the covariance matrix, $\Sigma_{0}$, is constant. Further, assume that the pricing kernel is given by

$$
-\log m_{t+1}=\Gamma_{0}+\Gamma_{1}^{\top} s_{t}+\frac{1}{2} \lambda\left(s_{t}\right)^{\top} \Sigma_{0} \lambda\left(s_{t}\right)+\lambda\left(s_{t}\right)^{\top} \Sigma_{0}^{1 / 2} \epsilon_{t+1} .
$$

The $k \times 1$ vector $\lambda\left(s_{t}\right)$ is now the "price-of-risk function" which will vary with the state according to

$$
\lambda\left(s_{t}\right)=\lambda_{0}+\lambda_{1} s_{t},
$$


where $\lambda_{0}$ is a $k \times 1$ vector and $\lambda_{1}$ is a $k \times k$ matrix of constant parameters. Note the two major differences between the pricing kernel in equation (21) and the specification in equation (14): The conditional correlation between the kernel, $m_{t+1}$, and the source of risk, $\epsilon_{t+1}$, is a linear function of the state variables, $s_{t}$, i.e., a state-dependent price of risk, and also that the pricing kernel in (21) contains the re-scaling term, $\frac{1}{2} \lambda\left(s_{t}\right)^{\top} \Sigma_{0} \lambda\left(s_{t}\right)$, that will preserve the log-linear structure for equilibrium bond prices.

Since the one-period bond price is the conditional expectation of the pricing kernel, we have:

$$
\begin{aligned}
b_{t}^{(1)} & =E_{t}\left[m_{t+1}\right] \\
& =\exp \left(-\Gamma_{0}-\Gamma_{1}^{\top} s_{t}-\frac{1}{2} \lambda\left(s_{t}\right)^{\top} \Sigma_{0} \lambda\left(s_{t}\right)\right) E_{t}\left[\exp \left(-\lambda\left(s_{t}\right)^{\top} \Sigma_{0}^{1 / 2} \epsilon_{t+1}\right)\right] \\
& =\exp \left(-\Gamma_{0}-\Gamma_{1}^{\top} s_{t}\right)
\end{aligned}
$$

This implies that the short interest rate is linear in the state variables:

$$
r_{t}=-\log b_{t}^{(1)}=\Gamma_{0}+\Gamma_{1}^{\top} s_{t}
$$

Similarly, bonds prices of any arbitrary maturity can be found through the recursive pricing relationship of equation (15), which yields bond-price coefficients that solve the equations analogous to equations (16) and (17):

$$
A(n)=\Gamma_{0}+A(n-1)+B(n-1)\left[(I-\Phi) \theta-\Sigma_{0} \lambda_{0}\right]-\frac{1}{2} B(n-1)^{\top} \Sigma_{0} B(n-1)
$$

and

$$
B(n)=\Gamma_{1}+\left[\Phi-\Sigma_{0} \lambda_{1}\right]^{\top} B(n-1)
$$

where, once again, $A(0)=B(0)=0$.

As before, it will be instructive to study the risk premium of a 2-period bond, which in this case is given by:

$$
\xi_{t}^{(2)}=-\frac{1}{2} \Gamma_{1}^{\top} \Sigma_{0}\left[\frac{1}{2} \Gamma_{1}+\lambda_{0}+\lambda_{1} s_{t}\right] .
$$

Note that in this case, the risk premium will be state dependent provided the price of risk is state dependent, i.e., $\lambda_{1} \neq 0$, and that the dynamics of the risk-premium process, $\xi_{t}^{(2)}$, is simply a rotation of the process for the state variable, $s_{t}$. For example, in the case of a single state variable, $k=1$, the risk premium follows a simple $\operatorname{AR}(1)$ process as before:

$$
\xi_{t+1}^{(2)}=(1-\Phi) \theta^{\xi}+\Phi \xi_{t}^{(2)}-\frac{1}{2} \Gamma_{1}^{\top} \Sigma_{0} \lambda_{1} \Sigma_{0}^{1 / 2} \epsilon_{t+1},
$$

where

$$
\theta^{\xi}=-\frac{1}{2} \Gamma_{1}^{\top} \Sigma_{0}\left[\frac{1}{2} \Gamma_{1}+\lambda_{0}+\lambda_{1} \theta\right]
$$


Once again, we have an endogenous risk-premium process that differs from McCallum's original exogenous specification only in the dependence of the drift and volatility on deeper parameters. The essential AR(1) structure is unchanged. Therefore, the linear rational expectations solution for the interest rate is of the same form as before, and we can solve for the resulting Fama-Bliss-like regression model parameters.

$$
E_{t}\left(r_{t+1}-r_{t}\right)=\frac{\mu_{f} \theta^{\xi}}{1-\mu_{f}}+2 \Phi \mu_{f}\left(r_{t}^{(2)}-r_{t}\right)
$$

The desire of the monetary authority to smooth interest rates both over time and across maturities, as specified by the McCallum Rule, results in an equilibrium model for the term structure in which the puzzling rejections of the expectations hypothesis have a very natural interpretation. Moreover, this interpretation is robust to the specification of an endogenous risk premium that inherits state dependence either from the stochastic volatility of the state variables or a state-dependent price of risk.

\section{Macroeconomic Models}

We develop two extensions of the New-Keynesian macroeconomic model in Clarida, Galí and Gertler (1999) that both defines the abstract state variables, $s_{t}$, and provides the desired link between the two monetary policy rules under consideration. In the first extension we allow for stochastic volatility, and in the second extension we allow for a stochastic priceof-risk matching the two earlier affine term structure models. The models consist of an aggregate bond demand, an inflation relationship and a monetary policy rule. The bond demand is modeled through the lifetime savings and investment problem of a representative consumer, and inflation is modeled through firms' staggered price setting with cost-push shocks. Monetary policy is modeled by an interest rate rule.

We start with the common elements of both models. Let $\hat{z}_{t}$ be the logarithm of the natural rate of output minus government spending, and $y_{t}$ the logarithm of the actual rate of output. The logarithm of the output gap $x_{t}$ is

$$
x_{t}=y_{t}-z_{t} .
$$

Defining Gov as government spending, the aggregate resource constraint is

$$
C_{t}=Y_{t}-\text { Gov }_{t} \text {. }
$$

Defining $z_{t}$ in as the natural rate of output less relative government spending,

$$
z_{t} \equiv \hat{z}_{t}+\log \left(1-\frac{\text { Gov }_{t}}{Y_{t}}\right)
$$


the logarithmic form of the aggregate resource constraint is

$$
c_{t}=x_{t}+z_{t}
$$

The natural rate of output less relative government spending, $z_{t}$, is determined exogenously. The output gap, $x_{t}$, is determined endogenously by the interest rate policy set by the monetary authority.

Define $P_{t}$ at the nominal price level at time $t$ and let $\pi_{t}=\ln P_{t}-\ln P_{t-1}$ be the inflation rate at time $t$. Inflation evolves according to

$$
\pi_{t}=\psi x_{t}+\kappa E_{t} \pi_{t+1}+u_{t}
$$

where $\psi$ is a positive constant measuring the impact of the current output gap on inflation and $0<\kappa<1$ is the effect of expected future inflation on current inflation. Equation (23) is derived from a model of firms' optimal price setting decisions with staggered price setting. Here, $u_{t}$ is a stochastic shock to firms' marginal costs, and we refer to $u_{t}$ as the cost-push shock. Iterating equation (23) forward, the equilibrium inflation rate is

$$
\pi_{t}=\sum_{i=0}^{\infty} \kappa^{i}\left(\psi E_{t}\left[x_{t+i}\right]+E_{t}\left[u_{t+i}\right]\right) .
$$

\subsection{A Macroeconomic Model with a Stochastic Volatility}

A representative consumer solves the intertemporal optimization problem:

$$
\max E_{t}\left[\sum_{i=0}^{\infty} \exp \{-\delta i\} \frac{C_{t+i}^{1-\gamma}}{1-\gamma}\right]
$$

subject to the standard intertemporal budget constraint. Here $\exp \{-\delta\}$ is the time preference parameter and $\gamma$ is the coefficient of relative risk aversion.

Letting $r_{t}$ be the continuously compounded one-period interest rate, the consumer's firstorder condition for one-period bond holding is:

$$
\exp \left\{-r_{t}\right\}=\exp \{-\delta\} E_{t}\left[\left(\frac{C_{t+1}}{C_{t}}\right)^{-\gamma}\left(\frac{P_{t}}{P_{t+1}}\right)\right] .
$$

Similar first-order conditions apply for the holdings of all financial securities. The logarithmic pricing kernel therefore is

$$
-\log m_{t+1}=\delta+\gamma\left(\Delta c_{t+1}\right)+\pi_{t+1},
$$

where $c_{t} \equiv \log C_{t}$ is the logarithm of consumption, and $\Delta$ is the difference operator. 
Using the aggregate resource constraint given by equation (22) and the inflation process given by equation (24), the logarithmic pricing kernel is:

$$
-\log m_{t+1}=\delta+\gamma\left(\Delta x_{t+1}+\Delta z_{t+1}\right)+\sum_{i=0}^{\infty} \kappa^{i}\left(\psi E_{t+1}\left[x_{t+1+i}\right]+E_{t+1}\left[u_{t+1+i}\right]\right) .
$$

Both $\Delta z_{t}$ and $u_{t}$ evolve exogenously. To describe the conditional volatility of the cost-push shock, $u_{t}$, we introduce an additional state variable $\eta_{t}$. The state variable $\eta_{t}$ can help predict the conditional volatility of cost-push shocks, and therefore contributes to the dynamics of the risk premium in the term structure.

To parallel the structure of the term structure model in Section 2, define the state vector

$$
s_{t} \equiv\left(\Delta z_{t}, \eta_{t}, u_{t}\right)^{\top} .
$$

The vector $s_{t}$ follows an autoregressive process with volatility of the "square root" form:

$$
s_{t+1}=(I-\Phi) \theta+\Phi s_{t}+\Sigma\left(s_{t}\right)^{1 / 2} \epsilon_{t+1},
$$

with

$$
\begin{gathered}
\Phi \equiv \operatorname{diag}\left\{\left[\Phi_{z}, \Phi_{\eta}, \Phi_{u}\right]\right\} \\
\theta \equiv\left[\theta_{z}, 0,0\right]^{\top} \\
\Sigma\left(s_{t}\right)=\operatorname{diag}\left\{\left(\alpha_{z}, \alpha_{\eta}, \alpha_{u}+\beta_{u \eta} \eta_{t}+\beta_{u u} u_{t}\right)\right\}
\end{gathered}
$$

and $\epsilon \sim \operatorname{iid} N(0, I)$.

The long-run mean of the cost-push shock $u$ and of the exogenous state variable $\eta$ are both zero. The long run mean of the growth of the natural rate of output growth less government spending is $\theta_{z}$.

The conditional volatilities of the growth of the natural rate of output and $\eta_{t}$ are both constant while the conditional volatility of the cost-push shock is time varying. The intuition of our results, however, is robust to incorporating time varying volatility in the growth of the natural rate of output or the shock $\eta_{t}$. Our parameterization is chosen for simplicity.

The dynamics of the risk premium depend only on the dynamics of the conditional volatility of the cost-push shock. If $\beta_{u \eta}=\beta_{u u}=0$, the conditional volatility of all the state variables is constant and the interest rate risk premiums are constant. If $\beta_{u \eta}=0$ and $\beta_{u u} \neq 0$, the conditional volatility of the cost-push shock only depends on the current level of the costpush; here the risk premium only depends on the cost-push shock. If $\beta_{u \eta} \neq 0$ and $\beta_{u u}=0$, the conditional volatility of the cost-push shock only depends on the current level of $\eta$; the risk premium only depends on $\eta$. If $\beta_{u \eta} \neq 0$ and $\beta_{u u} \neq 0$ the risk premium depends on both $u$ and $\eta$.

Both the output gap and the inflation rate are determined endogenously. The monetary authority sets the interest rate to respond to the current values of the state variables. 
The current output gap adjusts so that the equilibrium bond demand derived from equation (25) holds. Inflation is set according to equation (24). Rational expectations holds in equilibrium; the representative agent's beliefs about the distribution of future output gaps and future inflation rates are consistent with the monetary authority's policy rule and the process followed by the state variables.

The monetary authority sets an interest rate policy that is an affine function of the state vector. We show in Proposition 1 that a version of such an interest rate rule implies that the current output gap and current inflation are linearly related to the cost-push shock $u_{t}$. If we use the framework developed by Clarida, Galí and Gertler (1999) to determine monetary policy, the output gap without commitment would depend only on the cost-push shock - see their equation (3.6), for example. The policy corresponds to their optimal monetary policy without commitment, but our approach can also be extended to allow for a fully state dependent monetary policy.

The monetary authority policy goal is an output gap proportional to the cost-push shock:

$$
x_{t}=F u_{t},
$$

where $F$ is a constant. Typically, $F<0$ to reflect the bank pursuing a "leaning against the wind" policy - see equations (3.3)-(3.5) in Clarida, Galí and Gertler (1999), for example. The consumption growth process that is consistent with this policy goal is

$$
\Delta c_{t+1}=\Delta z_{t+1}+D \Delta u_{t+1},
$$

and the inflation process that is consistent with this policy goal is

$$
\pi_{t}=G u_{t},
$$

where

$$
G=\frac{\psi F+1}{1-\kappa \Phi_{u}}
$$

It is worth noting at this point that in our structural macroeconomic models, an implication of this monetary policy rule is that the output gap, $x_{t}$, and inflation, $\pi_{t}$, are perfectly correlated. Therefore, a Taylor Rule that would implement such a policy, as described below, will have no independent role for these two variables (or their expectations). Since empirical research typically demonstrates that Taylor Rules fitted to historical data do, in fact, vary independently on these two dimensions, this theoretical restriction may provide a point of tension for fitting the structural model to data. Note also, that our analysis can easily accommodate a richer monetary policy rule in which the monetary authority responds to more than the cost-push shock, provided this rule is linear, however, we do not consider that extension in this paper.

Since both consumption growth and inflation are jointly log-normally distributed, the interest rate is equal to

$$
r_{t}=\delta+\gamma E_{t}\left[\Delta c_{t+1}\right]+E_{t}\left[\pi_{t+1}\right]-\frac{1}{2} \gamma^{2} \operatorname{var}_{t}\left(\Delta c_{t+1}\right)-\frac{1}{2} \operatorname{var}_{t}\left(\pi_{t+1}\right)-\gamma \operatorname{cov}_{t}\left(\Delta c_{t+1}, \pi_{t+1}\right) .
$$


Using the output gap and the inflation rate, we can compute the logarithm of the pricing kernel and interest rate feedback rule, which leads us to our next set of results, summarized in the following proposition.

Proposition 1 Suppose that the output gap is a linear function of the cost-push shock, with coefficient $F$. Then, the pricing kernel is

$$
-\log m_{t+1}=\Gamma_{0}+\Gamma_{1}^{\top} s_{t}+\lambda^{\top} \Sigma\left(s_{t}\right)^{1 / 2} \epsilon_{t+1},
$$

with

$$
\begin{gathered}
\Gamma_{0}=\delta+\gamma\left(1-\Phi_{z}\right) \theta_{z}, \\
\Gamma_{1}=\left[\gamma \Phi_{z}, 0,(\gamma F+G) \Phi_{u}-\gamma F\right]^{\top},
\end{gathered}
$$

and

$$
\lambda=[\gamma, 0, \gamma F+G]^{\top}
$$

The interest rate is

$$
r_{t}=\Gamma_{0}-\frac{1}{2} \gamma^{2} \alpha_{z}-\frac{1}{2}(\gamma F+G)^{2} \alpha_{u}+\left(\Gamma_{1}^{\top}-\frac{1}{2}(\gamma F+G)^{2}\left[0, \beta_{u \eta}, \beta_{u u}\right]\right) s_{t} .
$$

Conversely, if the monetary authority sets interest rates according to equation (31), then the output gap and inflation rate follow as in equations (27) and (29).

Proof: The solutions for the pricing kernel follows by substituting the output gap and inflation solutions into the pricing kernel, equation (26). The resulting interest rate and risk premium follow from the expressions for the affine model developed in Section 3. The converse follows from inverting the bond demand equation for the current output gap, given a linear form for expected output and expected inflation and matching terms.

An affine feedback rule for the interest rate results in an output gap that is linear in the cost-push shock and an affine term structure with stochastic volatility. The monetary authority's policy goal is given by $F$. The interest rate feedback rule, equation (31), depends on $F$. The interest rate risk premium depends on the conditional second moments of consumption growth and inflation. But equilibrium consumption and inflation volatility themselves depend on the policy goal - the interest rate risk premium therefore depends on the policy goal.

The interest rate is an affine function of the state vector: the current growth rate of natural output less government consumption $\Delta z_{t}$, the current cost-push shock $u_{t}$ and the exogenous shock $\eta_{t}$. The only state variable with a time-varying conditional volatility is the cost-push shock. The time-variation in the risk premium therefore only depends on the state variables that predict the conditional volatility of the cost-push shock - the current level of the costpush shock and the exogenous shock. Quite naturally then, the interest rate must be 
correlated to the risk premium in order to achieve the policy goal. In Section 5, we show that the resulting interest rate feedback rule can be written as either a McCallum Rule in which the interest rate is set with yield spreads and a lag of the interest rate, or as a simple Taylor-type rule in which the interest rate depends on the expected inflation rate, expected output growth and the exogenous variable $\eta_{t}$.

\subsection{A Macroeconomic Model with Stochastic Price of Risk}

We now modify the macroeconomic model developed in the last section to allow for a timevarying price of risk. We accomplish this by introducing a stochastic preference shock into the model. The stochastic preference shock takes the form of stochastic risk-aversion and can be interpreted as a form of external habits.

The representative consumer's preferences are

$$
E_{t}\left[\sum_{i=0}^{\infty} \exp \{-\delta i\} \frac{C_{t+i}^{1-\gamma}}{1-\gamma} Q_{t+i}\right]
$$

with $Q_{t}$ the time $t$ preference shock. The preference shock is taken as exogenous by the representative consumer. The consumer's first-order condition for one-period bond holding is:

$$
\exp \left\{-r_{t}\right\}=\exp \{-\delta\} E_{t}\left[\left(\frac{C_{t+1}}{C_{t}}\right)^{-\gamma}\left(\frac{P_{t}}{P_{t+1}}\right)\left(\frac{Q_{t+1}}{Q_{t}}\right)\right] .
$$

The logarithmic pricing kernel therefore is

$$
-\log m_{t+1}=\delta+\gamma\left(\Delta c_{t+1}\right)+\pi_{t+1}-\Delta q_{t+1},
$$

where $\Delta q_{t+t} \equiv \log q_{t+t}-\log q_{t}$ is the change in the logarithm of the preference shock. We impose a specific stochastic structure on the preference shock and the other primitives of the economy so that the pricing kernel has an affine price of risk.

The stochastic preference shock is linearly related to shocks in consumption growth, with a coefficient that varies linearly with the current level of consumption growth and an exogenous variable $\eta_{t}$ :

$$
-\Delta q_{t+1}=\frac{1}{2}\left(\phi_{c} \Delta c_{t}+\phi_{\eta} \eta_{t}\right)^{2} \operatorname{var}_{t} \Delta c_{t+1}+\left(\phi_{c} \Delta c_{t}+\phi_{\eta} \eta_{t}\right)\left(\Delta c_{t+1}-E_{t} \Delta c_{t+1}\right) .
$$

The preference shock allows for external habit formation and exogenously varying stochastic risk aversion. The representative consumer's overall sensitivity to consumption growth is $\gamma+\left(\phi_{c} \Delta c_{t}+\phi_{\eta} \eta_{t}\right)$. The term $\left(\phi_{c} \Delta c_{t}+\phi_{\eta} \eta_{t}\right)$ can therefore be interpreted as the stochastic part of the representative agent's risk aversion.

The coefficient $\phi_{c}$ measures the sensitivity of the representative agent's level of risk-aversion to the current growth rate of aggregate consumption, and is a form of sensitivity to external 
habits, as in Campbell and Cochrane (1999). The coefficient $\phi_{\eta}$ measures the sensitivity of the representative agent's level of risk aversion to the current exogenous preference shock $\eta_{t}$.

The term $-\frac{1}{2}\left(\phi_{c} \Delta c_{t}+\phi_{\eta} \eta_{t}\right)^{2} \operatorname{var}_{t} \Delta c_{t+1}$ in the stochastic preference shocks implies that the conditional mean of the growth of the preference shock is one:

$$
E_{t}\left[\frac{Q_{t+1}}{Q_{t}}\right]=1
$$

The natural rate of output and the cost-push shocks both follow autoregressive processes with constant conditional volatilities. As in the macroeconomic model with stochastic volatility, the monetary authority's policy target is an output gap proportional to the cost push shock with coefficient $F$, as in equation (27). Consumption growth consistent with the policy target is the same as in the macroeconomic model with stochastic volatility in equation (28).

The state vector for the macroeconomic model with stochastic price of risk is

$$
s_{t} \equiv\left(\Delta z_{t}, \eta_{t}, u_{t}, u_{t-1}\right)^{\top} .
$$

Note that the state vector now includes one lag of the cost-push shock to allow for the effects of lagged consumption on the representative consumer's risk-aversion. The stochastic process for $s_{t}$ is given by the following vector autoregression with constant volatility:

$$
s_{t+1}=(I-\Phi) \theta+\Phi s_{t}+\Sigma_{0}^{1 / 2} \epsilon_{t+1},
$$

with

$$
\begin{gathered}
\Phi=\left[\begin{array}{cccc}
\Phi_{z} & 0 & 0 & 0 \\
0 & \Phi_{\eta} & 0 & 0 \\
0 & 0 & \Phi_{u} & 0 \\
0 & 0 & 1 & 0
\end{array}\right], \\
\theta^{\top}=\left[\theta_{z}, 0,0,0\right], \\
\Sigma_{0}=\operatorname{diag}\left\{\left(\alpha_{z}, \alpha_{\eta}, \alpha_{u}, 0\right)\right\},
\end{gathered}
$$

and $\epsilon \sim N(0, I)$.

Using the dynamics of the state variables and the output gap process, the inflation process consistent with the monetary authorities policy goal is the same affine function of the costpush shock as in the model with time-varying risk given by equations (30) and (29).

The logarithmic pricing kernel and interest rate rule is summarized in the next proposition.

Proposition 2 Suppose that the output gap is a linear function of the cost-push shock, with coefficient $F$. Then, the pricing kernel is

$$
-\log m_{t+1}=\Gamma_{0}+\Gamma_{1}^{\top} s_{t}+\frac{1}{2} \lambda^{\top}\left(s_{t}\right) \Sigma_{0} \lambda\left(s_{t}\right)+\lambda^{\top}\left(s_{t}\right) \Sigma_{0}^{1 / 2} \epsilon_{t+1}
$$


with

$$
\begin{gathered}
\Gamma_{0}=\delta+\gamma\left(1-\Phi_{z}\right) \theta_{z}-\frac{1}{2}\left(\gamma^{2} \alpha_{z}+(\gamma F+G)^{2} \alpha_{u}\right), \\
\Gamma_{1}=\left[\gamma \Phi_{z}, 0,(\gamma F+G) \Phi_{u}-\gamma F, 0\right]^{\top}-\left(\gamma \alpha_{z}+(\gamma F+G) \alpha_{u} F\right)\left[\phi_{c}, \phi_{\eta}, \phi_{c} F,-\phi_{c} F\right]^{\top},
\end{gathered}
$$

and

$$
\lambda\left(s_{t}\right)=\lambda_{0}+\lambda_{1} s_{t},
$$

where

$$
\begin{gathered}
\lambda_{0}=[\gamma, 0, \gamma F+G, 0]^{\top}, \\
\lambda_{1}=\left[\begin{array}{cccc}
\phi_{c} & \phi_{\eta} & \phi_{c} F & -\phi_{c} F \\
0 & 0 & 0 & 0 \\
\phi_{c} F & \phi_{\eta} F & \phi_{c} F^{2} & -\phi_{c} F^{2} \\
0 & 0 & 0 & 0
\end{array}\right] .
\end{gathered}
$$

The interest rate is

$$
r_{t}=\Gamma_{0}+\Gamma_{1}^{\top} s_{t} .
$$

Conversely, if the monetary authority sets interest rates according to equation (33), then the output gap and inflation rate follow as in equations (27) and (29).

Proof: The solutions for the pricing kernel follows by substituting the output gap and inflation solutions into the pricing kernel, equation (32). The resulting interest rate and risk premium follow from the expressions for the affine model developed in Section 3. The converse follows from inverting the bond demand equation for the current output gap, given a linear form for expected output and expected inflation and matching terms.

A linear feedback rule for the interest rate results in an output gap that is linear in the cost-push shock and an affine term structure model with a time-varying price-of-risk.

The monetary authority's policy goal is given by $F$. The interest rate feedback rule given by equation (33) therefore depends on $F$. The interest rate is an affine function of the state vector: the current growth rate of natural output less government consumption $\Delta z_{t}$, the current cost-push shock $u_{t}$, the lagged cost-push shock $u_{t-1}$ and the exogenous shock $\eta_{t}$. The risk premium depends on the representative consumer's risk aversion which is driven by the current consumption growth rate and the current value of the exogenous shock $\eta$. But consumption depends on the current growth rate in the natural rate of output less government consumption and the current growth in the output gap, which itself depends on the current and lagged levels of the cost-push shock. The time-variation in the risk premium therefore depends on the current growth rate in the natural level of output, the current level of the cost-push shock, the lagged level of the cost-push shock and the current value of the exogenous variable. Quite naturally then, the interest rate must be correlated with the risk premium in order to achieve the policy goal. In Section 5, we show that resulting interest rate feedback rule can be written as either a McCallum Rule in which the interest rate is correlated to the risk premium, or as a Taylor Rule in which the interest rate depends on the inflation rate, the output gap and a policy shock. 


\section{The Taylor Rule and the McCallum Rule in the Macroe- conomic Models}

In the macroeconomic model with time-varying volatility, the interest rate and the risk premium are both affine functions of the state variables, with coefficients that depend on the policy goal. But the inflation rate, the output gap, the growth in the natural rate of output and the exogenous shock $\eta$ are also affine functions of the state variables. As a consequence, the interest rate rule can be expressed as an affine function of the expected growth in the natural rate of output, expected inflation and the exogenous shock. Such a representation of the interest rate is a simple form of a forward looking Taylor Rule for the interest rate:

$$
r_{t}=\tau_{0}+\tau_{1} E_{t} \Delta z_{t+1}+\tau_{2} E_{t} \pi_{t+1}+\tau_{3} \eta_{t},
$$

where the parameters of this rule as a function of the deeper parameters of the model are given by

$$
\begin{aligned}
\tau_{0} & =\delta+\gamma^{2} \alpha_{z}-\frac{1}{2}(\gamma F+G)^{2} \alpha_{u} \\
\tau_{1} & =\gamma \\
\tau_{2} & =1+\left(\frac{\gamma F}{G}\right)\left(\frac{\Phi_{u}-1}{\Phi_{u}}\right)-\frac{1}{2} \frac{(\gamma F+G)^{2}}{G \Phi_{u}} \beta_{u u} \\
\tau_{3} & =-\frac{1}{2}(\gamma F+G)^{2} \beta_{u \eta} .
\end{aligned}
$$

The central bank's policy goal therefore affects the response of the interest rate to expected inflation and the exogenous shock. As noted in the previous section, unlike many specifications of the Taylor Rule, there is no scope in our structural model for including both expected inflation and the expected output gap, since the monetary policy rule induces perfect correlation across these two variables. A more complex monetary policy that generalized the simple one-dimensional optimal policy rule in Clarida, Galí and Gertler (1999) could be accommodated in our framework in a natural fashion. In some sense, therefore, our analysis can be thought of as exploring how interest rate feedback rules based on macroeconomic variables can be equivalent to interest rate feedback rules based on the term structure. We nonetheless refer to the former as a Taylor Rule, with the caveat mentioned above.

In the macroeconomic model with a time-varying price of risk, the interest rate and the risk premium are both affine functions of the state variables, with coefficients that depend on the policy goal. Here, the state variables are the growth in the natural rate of output, the exogenous variable $\eta_{t}$, the cost-push shock and one lag of the cost-push shock. But the inflation rate, expected growth in the natural rate of output gap, growth in the natural rate of output and the exogenous shock $\eta$ are also affine functions of the state variables. As a consequence, the interest rate rule can be expressed as an affine function of the expected growth in the natural rate of output, expected inflation, lagged inflation and the exogenous shock. Such a representation of the interest rate is a simple form of a forward looking Taylor Rule for the interest rate:

$$
r_{t}=\hat{\tau}_{0}+\hat{\tau}_{1} E_{t} \Delta z_{t+1}+\hat{\tau}_{2} E_{t} \pi_{t+1}+\hat{\tau}_{3} \eta_{t}+\hat{\tau}_{4} \pi_{t-1},
$$


where the Taylor Rule parameters are given by

$$
\begin{aligned}
& \hat{\tau}_{0}=\delta+\frac{\gamma \alpha_{z}+(\gamma F+G) \alpha_{u} F}{\Phi_{z}} \phi_{c}\left(1-\Phi_{z}\right) \theta_{z}-\frac{1}{2} \gamma^{2} \alpha_{z}-\frac{1}{2}(\gamma F+G)^{2} \alpha_{u} \\
& \hat{\tau}_{1}=\gamma-\frac{\gamma \alpha_{z}+(\gamma F+G) \alpha_{u} F}{\Phi_{z}} \phi_{c} \\
& \hat{\tau}_{2}=1+\left(\frac{\gamma F}{G}\right)\left(\frac{\Phi_{u}-1}{\Phi_{u}}\right)-\frac{\gamma \alpha_{z}+(\gamma F+G) \alpha_{u} F}{\Phi_{u} G} \phi_{c} F \\
& \hat{\tau}_{3}=-\left(\gamma \alpha_{z}+(\gamma F+G) \alpha_{u} F\right) \phi_{\eta} \\
& \hat{\tau}_{4}=\frac{\gamma \alpha_{z}+(\gamma F+G) \alpha_{u} F}{G} \phi_{c} F .
\end{aligned}
$$

Note that given the expanded state space for this model, we also include lagged inflation in this policy rule, and that, once again, the output gap does not appear as an independent variable in this equation given its perfect correlation with inflation.

Since both macroeconomic models result in affine term structure models, the results of Section 3.1 can be used to construct a McCallum Rule for each model. Revisiting equation (12), the current short rate $r_{t}$ can be expressed in terms of its lag $r_{t-1}$ and a vector of current yield spreads $r_{t}^{(k)}-r_{t}$ :

$$
\begin{aligned}
r_{t} & =\left(\mathcal{C}_{1}-\mathcal{D}_{12} \mathcal{D}_{22}^{-1} \mathcal{C}_{2}\right)+\left(\mathcal{D}_{11}-\mathcal{D}_{12} \mathcal{D}_{22}^{-1} \mathcal{D}_{21}\right) r_{t-1} \\
& +\mathcal{D}_{12} \mathcal{D}_{22}^{-1}\left[r_{t}^{(2)}-r_{t}, r_{t}^{(3)}-r_{t}, \ldots, r_{t}^{(k)}-r_{t}\right]^{\top} \\
& +\left(\mathcal{S}_{1}-\mathcal{D}_{12} \mathcal{D}_{22}^{-1} \mathcal{S}_{2}\right) \epsilon_{t} .
\end{aligned}
$$

The McCallum Rule links to the monetary authority's policy goal $F$ through its dependency on $\mathcal{C}$ and $\mathcal{D}$ as can be seen in Propositions 1 and 2 where the affine term-structure parameters are expressed in terms of each economy's primitives. In particular, both the stochastic volatility and stochastic price-of-risk macroeconomic models' McCallum Rules can be expressed in terms of the lagged interest rate and two yield spreads. ${ }^{6}$

Given the McCallum Rule involves expressing the interest rate policy rule in terms of properties of the current and lagged yield curve, it is difficult to make direct analytical comparisons with a Taylor Rule given the coefficients of both the McCallum Rule and the Taylor Rule are nonlinear functions of the monetary authority's policy goal $F$. To facilitate a comparison of the two monetary rules, we explore the behavior of each rule numerically in the next section.

\footnotetext{
${ }^{6}$ Although the stochastic price-of-risk model has four state variables, the inclusion of the lagged cost-push shock $u_{t-1}$ leads to the autocorrelation matrix $\Phi$ having rank three implying that the matrix $\mathcal{D}$ also has rank three. This implies that the McCallum Rule for the stochastic price-of-risk model can be constructed using the lagged interest rate plus only two yield spreads.
} 


\section{$6 \quad$ Numerical Examples}

To explore the highly nonlinear relationships between Taylor Rule and McCallum Rule parameters and the deep parameters of the underlying macroeconomy, we calculate some suggestive numerical examples. Note that these examples are strictly illustrative and should not be thought of as either empirical fitting or calibration exercises.

Table 1 reports instances of the two macroeconomic models (i.e., the stochastic volatility and the stochastic price-of-risk models), that have structural parameters that simultaneously generate average term structures that have the basic features of observed data (namely a positive but decreasing slope as a function of maturity), and a regression coefficient for a Fama-Bliss regression that is significantly lower than 1 . Without a proper empirical analysis of these models, which is beyond the scope of the current exercise, it is difficult to pin down precise parameter values, however, we can nonetheless explore the comparative properties of Taylor and McCallum Rules as mechanism for implementing a particular monetary policy rule. Recall that monetary policy is summarized by a single parameter, $F$, whose negative value implies a "leaning against the wind" monetary policy in the face of an exogenous cost-push shock. We constrained the choice of other structural parameters to values that are reasonable given the analysis in Clarida, Galí and Gertler (2000). Specifically, we set the parameters of the inflation equation such that the output elasticity of inflation, $\psi$, is equal to 0.3 , and the expected inflation elasticity, $\kappa$, is equal to 0.99 . The inflation shock is assumed to be fairly persistent with an autocorrelation parameter, $\Phi_{u}$, set equal to 0.9. The standard deviations of the of the innovations to output, inflation, and $\eta$ are all fixed at $3 \%$, which is appropriate for an annual scale. Finally, the risk aversion parameter, $\gamma$, is set at 10, which is implies a significant amount of curvature in the representative agent's utility function, an assumption that is quite common in the empirical finance literature. The benefit a high risk aversion coefficient is obviously to enhance the ability of these models to generate sizeable risk premiums. The cost, however, is in the tight connection between this coefficient and the coefficient on the expected change in the natural rate of output, $E_{t} z_{t+1}$, in the Taylor Rules described in equations (34) and (35). In other words, these Taylor Rule coefficients will seem larger in our specifications with $\gamma=10$ than in empirically fitted Taylor Rules that do not impose this theoretical restriction. This will clearly be a point of tension in any empirical implementation of either of our structural models.

What we see in this table is that for the stochastic volatility models (the second column), it is relatively straightforward to find an economy in which the McCallum Rule and the Taylor Rule implement the same monetary policy with parameters of the rules equal to what appear to be reasonable values. The parameters of the Taylor Rule in the stochastic price-of-risk model (the third column) also seem quite reasonable. Note, however, that although this pattern holds for the McCallum Rule parameters in the stochastic volatility model, in the stochastic price-of-risk model, the McCallum Rule parameters have rather incredible values. It is difficult to gain much intuition for the source of this odd result given the highly nonlinear mapping from deep parameters to McCallum Rule parameters, since it is well known that risk premiums across maturities, especially the short maturities considered in these examples, are highly correlated. It may simply be the case that an 
extreme value for one parameter is simply offsetting the implication of an extreme value of another parameter. Nonetheless, although the McCallum Rule in this example implements the monetary policy rule as well as the Taylor Rule, its rather odd coefficients would make it a difficult rule to communicate to practitioners. An obvious solution to this problem is to search for a rotation of the state-space for which the dimensions of a McCallum Rule are closer to being orthogonal, which is likely to generate parameter value that are much more natural. We leave further exploration of this point to future research.

Note that in both models, the Fama-Bliss regression parameter is substantially lower than 1 , which is consistent with the empirical anomaly that motivated McCallum's original work.

Finally, in Figures 1 and 2, we explore the sensitivity of Taylor Rule and McCallum Rule parameters to alternative monetary policy rules, i.e, values of $F$. As shown in Clarida, Galí and Gertler (1999), this parameter is actually a reduced form for deeper structural parameters of the monetary authority's the objective function. Given the parameters of our inflation equation, we consider a range of stricter "leaning against the wind" policies, i.e., more negative values of $F$, that are generally consistent with the Clarida, Galí and Gertler (1999) model. What we see from these figures is that the Taylor Rule is relatively robust in the sense that the parameter values of the rule do not change dramatically as the underlying policy objective changes. On the other hand, given the curious behavior of the McCallum Rule parameters described above, we see that these parameters change dramatically as a function of $F$, but typically in offsetting directions. Again, these McCallum Rules are implementing the same monetary policy, but in a very unintuitive fashion.

\section{Conclusion}

We have shown that the McCallum (1994a) result that the expectations hypothesis, when adjusted for an active interest-rate monetary policy rule that has a yield-curve smoothing component, matches observed dynamic patterns in the term structure than the expectations hypothesis alone, extends to the case of a broad class of endogenous risk-premium models. These models include both stochastic volatility specifications as well as stochastic price-of-risk specifications in the Duffie and Kan (1996) class of arbitrage-free affine termstructure models. In addition, we have shown that simple New-Keynesian macroeconomics model along the lines of Clarida, Galí, and Gertler (1999) can be used as a macroeconomic foundation for identifying the relevant state variables and parameters of a latent-variable or unobservable-factor model of the term structure. We consider two such models that have reduced forms that correspond to the two affine models we study. Within these macroeconomic term-structure model, we show when the McCallum Rule is equivalent to the Taylor Rule.

In our model, Taylor Rules and McCallum Rules can implement the same monetary policy goals. Both rules are nonlinear functions of the deep parameters of the economy. The McCallum Rule can lead to extreme coefficients on interest-rate spreads, with the coefficients sensitive to changes in the deep parameters of the economy. The Taylor Rule tends to 
have much more robust coefficients. But the two types of interest-rate rules have different informational requirements. The McCallum Rule is based on high-quality financial data available in real time while the Taylor Rule requires more slowly gathered macroeconomic information. Given the informational advantages to using information from the term structure to set rates, it would be useful to further study what kinds of monetary policy can be implemented using the term structure. What are the most informative points on the term structure for monetary policy? How many points on the term structure should be used? How well would such a policy fit empirical data - both macroeconomic and term structure? What are the implications of richer models of optimal monetary policy. We leave those questions for further work. 


\section{References}

Ang, A. and M. Piazzesi. (2003). "A No-Arbitrage Vector Autoregression of Term Structure Dynamics with Macroeconomic and Latent Variables," Journal of Monetary Economics, 50, May, 745-787.

Ang, A., S. Dong and M. Piazzesi. (2004). "No-Arbitrage Taylor Rules," Working Paper, Columbia University.

Backus, D., S. Foresi, A. Mozumdar and L. Wu. (2001). "Predictable Changes in Yields and Forward Rates," Journal of Financial Economics, 59, 281-311.

Brandt, M. and D. Chapman (2003). "Comparing Multifactor Models of the Term Structure," working paper, Duke University.

Campbell, J.Y. and J. H. Cochrane. (1999). "By Force of Habit: A Consumption-Based Explanation of Aggregate Stock Market Behavior," Journal of Political Economy, 107, 205-51.

Clarida, R., J. Galí and M. Gertler. (1999). "The Science of Monetary Policy: A New Keynesian Perspective," Journal of Economic Literature, 37, 1661-1707.

Clarida, R., J. Galí and M. Gertler. (2000). "Monetary Policy Rules and Macroeconomic Stability: Evidence and Some Theory," The Quarterly Journal of Economics, 115, $147-180$.

Cochrane, J. and M. Piazzesi. (2002). "The Fed and Interest Rates - A High- Frequency Identification," American Economic Review, Papers and Proceedings, 92, May, 90-95.

Dai, Q. (2000). "From Equity Premium Puzzle to Expectations Puzzle: A General Equilibrium Production Economy with Stochastic Habit Formation," Working Paper, Stern School of Business, New York University.

Dai, Q. and T. Philippon. (2004). "Government Deficits and Interest Rates: A NoArbitrage Structural VAR Approach," working paper, NYU.

Dai, Q. and K. Singleton. (2000). "Specification Analysis of Affine Term Structure Models," Journal of Finance, 55, 1943-1978.

Dai, Q. and K. Singleton. (2002). "Expectation Puzzles, Time-Varying Risk Premia, and Affine Models of the Term Structure," Journal of Financial Economics, 63, 415-441.

Dai, Q. and K. Singleton. (2003). "Term Structure Dynamics in Theory and Reality," Review of Financial Studies, 16, 631-678.

Duffee, G.R. (2002). "Term premia and interest rate forecasts in affine models," Journal of Finance, 57, 405-443.

Duffie, D. and R. Kan. (1996). "A Yield-Factor Model of Interest Rates," Mathematical Finance, 6, pp. 379-406.

Estrella, A. and F. S. Mishkin. (1997). "The Predictive Power of the Term Structure of Interest Rates in Europe and the United States: Implications for the European Central Bank," European Economic Review, 41, 1375-1401. 
Evans, C. L. and D. A. Marshall. (1998). "Monetary Policy and the Term Structure of Nominal Interest Rates: Evidence and Theory," Carnegie-Rochester Conference Series on Public Policy, 49, 53-111.

Evans, C. L. and D. A. Marshall. (2001). "Economic Determinants of the Term Structure of Nominal Interest Rates," Working paper, Federal Reserve Bank of Chicago, Chicago, IL.

Fama, E. F. and R. R. Bliss. (1987). "The Information in Long-Maturity Forward Rates," The American Economic Review, 77, September, 680-692.

Goodfriend, M. (1991). "Interest Rates and the Conduct of Monetary Policy," CarnegieRochester Conference Series on Public Policy, 34, 7-30.

Goodfriend, M. (1993). "Interest Rate Policy and the Inflation Scare Problem: 1979-1992," Federal Reserve Bank of Richmond Economic Quarterly, 79, Winter, 1-23.

Hördahl, P., O. Tristani, and D. Vestin. (2003). "A Joint Econometric Model of Macroeconomic and Term Structure Dynamics," working paper, European Central Bank.

Kugler, P. (1997). "Central Bank Policy Reaction and the Expectations Hypothesis of the Term Structure," International Journal of Financial Economics, 2, 217-224.

Mankiw, N. G. and J. A. Miron. (1986). "The Changing Behavior of the Term Structure of Interest Rates," The Quarterly Journal of Economics, 101, 211-228.

McCallum, B. T. (1994a). "Monetary Policy and the Term Structure of Interest Rates," NBER Working Paper No. 4938.

McCallum, B. T. (1994b). "A Reconsideration of the Uncovered Interest Rate Parity Relationship," Journal of Monetary Economics, 33, 105-132.

Piazzesi, M. (2001). "An Econometric Model of the Yield Curve with Macroeconomic Jump Effects," NBER Working Paper No. 8246.

Piazzesi, M. and E. Swanson. (2004). "Futures Prices as Risk-Adjusted Forecasts of Monetary Policy," NBER Working Paper No. 10547.

Rudebusch, G. (1998). "Do Measures of Monetary Policy in a VAR Make Sense?" International Economic Review, 39, 907-31.

Rudebusch, G. and T. Wu. (2004). "A Macro-Finance Model of the Term Structure, Monetary Policy, and the Economy," Working Paper, Federal Reserve Bank of San Francisco.

Singleton, K. J. (2005). "Dynamic Asset Pricing Models: Econometric Specification and Empirical Assessments," manuscript, Stanford University (Princeton University Press, forthcoming).

Taylor, J. B. (1993). "Discretion versus Policy Rules in Practice," Carnegie-Rochester Conference Series on Public Policy, 39, December, 195-214.

Wachter, J. (2004). "A Consumption-Based Model of the Term Structure of Interest Rates," Working Paper, Wharton School of Business, University of Pennsylvania. 
Stoch. Volatility Stoch. Price of

Model Parameters Model Risk Model

$\begin{array}{lrr}F & -1.131 & -1.142 \\ \delta & 0.020 & -0.063 \\ \Phi_{z} & 0.901 & -0.267 \\ \Phi_{\eta} & 0.896 & -0.238 \\ \theta_{z} & 0.018 & 0.008 \\ \beta_{u u} & 0.0009 & - \\ \beta_{u \eta} & -0.0943 & - \\ \phi_{c} & - & -10 \\ \phi_{\eta} & - & -165\end{array}$

Taylor Rule Coefficients

\begin{tabular}{lrr}
\hline & & \\
$E_{t}\left[\Delta z_{t+1}\right]$ & 10.000 & 9.455 \\
$E_{t}\left[\pi_{t+1}\right]$ & 1.445 & 1.180 \\
$\pi_{t}$ & - & 0.028 \\
$\eta_{t}$ & -0.012 & 2.405 \\
McCallum Rule Coefficients & & \\
\hline & & \\
$r_{t-1}$ & 0.931 & -2.932 \\
$r_{t}^{(2)}-r_{t}$ & 0.239 & 0.350 \\
$r_{t}^{(3)}-r_{t}$ & 0.228 & 25.532 \\
Term-Structure Properties & & \\
\hline & & \\
Fama-Bliss Coefficient & & \\
& 0.563 & \\
$E\left[r_{t}\right]$ & & \\
$E\left[r_{t}^{(2)}-r_{t}\right]$ & $4.50 \%$ & $1.50 \%$ \\
$E\left[r_{t}^{(3)}-r_{t}\right]$ & $1.94 \%$ & $1.10 \%$ \\
\end{tabular}

Table 1: Policy Rule Examples. Common parameters across models: $\psi=0.3, \kappa=0.99$, $\Phi_{u}=0.9, \alpha_{z}=\alpha_{\eta}=\alpha_{u}=0.0009, \gamma=10$. 

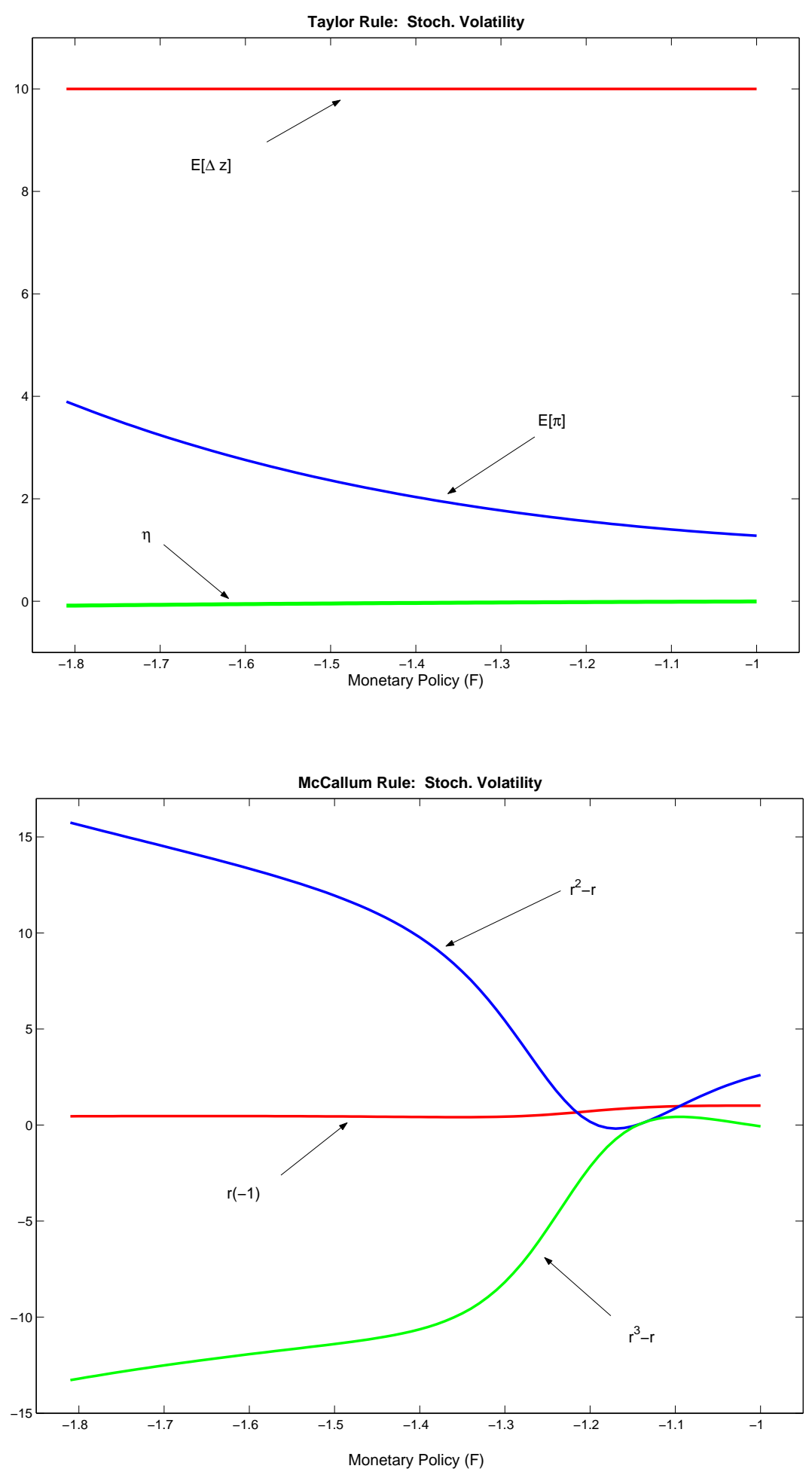

Figure 1: Policy Rules - Stochastic Volatility Model. Parameters: $\delta=0.020, \psi=0.3$, $\kappa=0.99, \theta_{z}=0.018, \Phi_{z}=0.901, \Phi_{\eta}=0.896, \Phi_{u}=0.9, \alpha_{z}=\alpha_{\eta}=\alpha_{u}=0.0009, \gamma=10$, $\beta_{u u}=0.0009, \beta_{u \eta}=-0.0943$. 

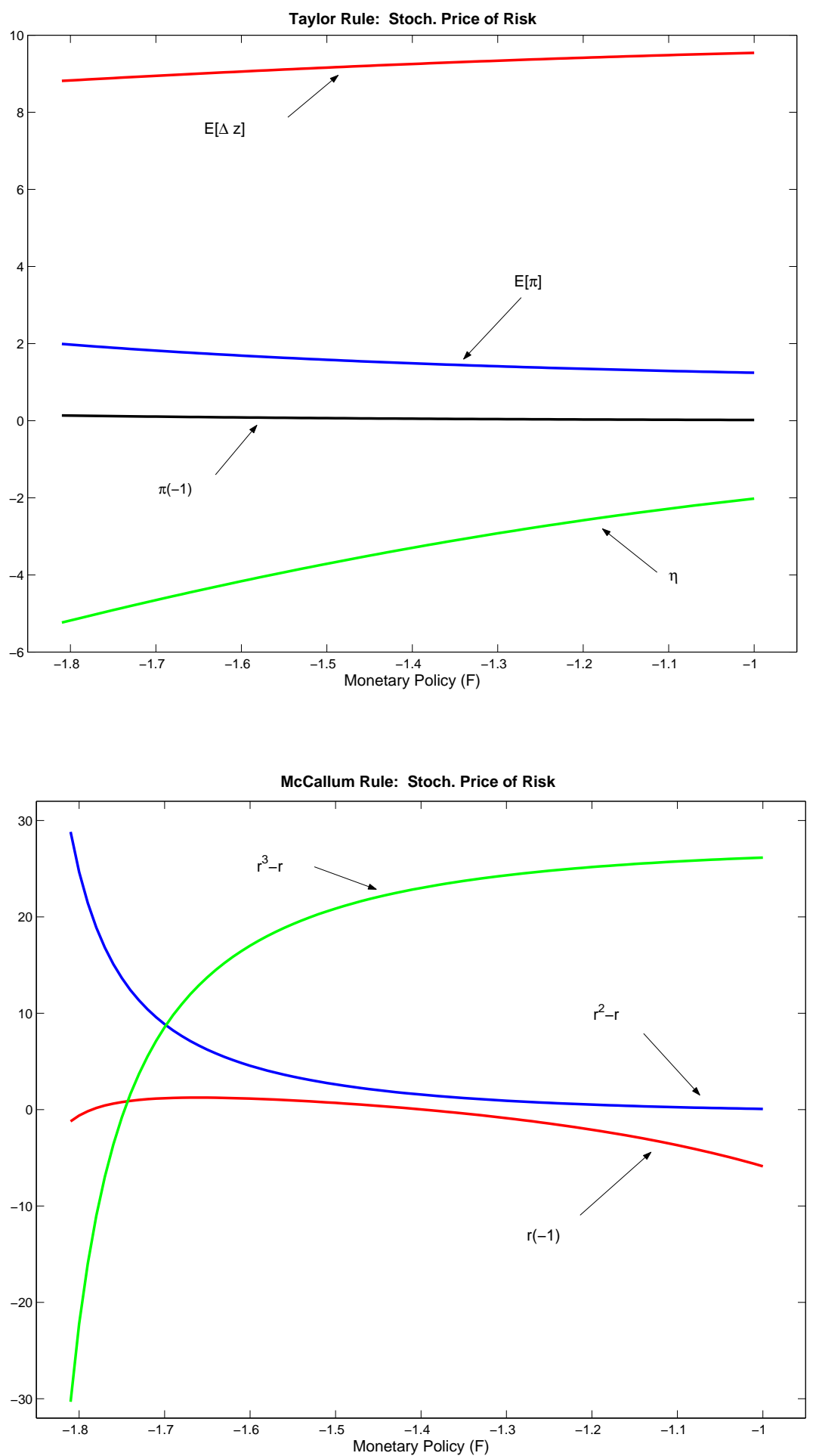

Figure 2: Policy Rules - Stochastic price-of-risk Model. Parameters: $\delta=-0.063, \psi=0.3$, $\kappa=0.99, \theta_{z}=0.008, \Phi_{z}=-0.267, \Phi_{\eta}=-0.238, \Phi_{u}=0.9, \alpha_{z}=\alpha_{\eta}=\alpha_{u}=0.0009, \gamma=10$, $\phi_{c}=-10, \phi_{\eta}=-165$. 